\title{
Cereblon attenuates DNA damage-induced apoptosis by regulating the transcription- independent function of p53
}

\author{
Liang Zhou ${ }^{1}$ and Guogiang $X u^{1}$
}

\begin{abstract}
Cereblon (CRBN) is the substrate receptor of the cullin 4-RING E3 ligase complex and has been employed for targeted protein degradation in the treatment of cancers. However, its normal physiological functions and molecular mechanism in the regulation of DNA damage response are largely unknown. Here we find that CRBN plays a protective role against DNA damage-induced apoptosis in cell lines and primary cells. Mechanistic studies demonstrate that although CRBN does not affect the ubiquitination and degradation of the tumor suppressor p53, it directly interacts with p53 and therefore, suppresses the interaction between p53 and anti-apoptotic regulators Bcl-2 and $\mathrm{BCl}-\mathrm{X}_{\mathrm{L}}$. CRBN depletion enhances the interaction between p53 and $\mathrm{BCl}-2 / \mathrm{BCl}-\mathrm{X}_{\mathrm{L}}$, reduces mitochondrial membrane potential, increases the cleavage of caspase-3 and poly(ADP-ribose) polymerase 1, and thus promotes DNA damageinduced apoptosis in cell lines and primary cells upon etoposide treatment. Moreover, Crbn knockout mice exhibit increased mortality upon etoposide challenge. Taken together, our data elucidate a novel molecular mechanism by which CRBN inhibits DNA damage response in vitro and in vivo. This work extends our understanding of the broad spectrum of physiological roles for CRBN and may suggest its potential application in the treatment of DNA damageassociated diseases.
\end{abstract}

\section{Introduction}

p53 is one of the most studied tumor suppressors, which is critical for the regulation of DNA damage-induced apoptosis $^{1-4}$. As a transcription factor, nuclear p53 promotes the expression of pro-apoptotic genes, such as apoptosis regulator $B A X^{5}$ and $\mathrm{Bcl}-2$-binding component 3 $P U M A^{6}$. Their increased protein products then initiate mitochondrial damage, reduce mitochondrial membrane potential (MMP), release cytochrome c, activate caspases, and lead to the cleavage of poly(ADP-ribose) polymerase 1 (PARP1) and apoptosis ${ }^{4,7}$. However, the nuclear localization signal deleted p53 can still promote apoptosis, indicating the important role of cytoplasm p53 in the

\footnotetext{
Correspondence: Guoqiang Xu (gux2002@suda.edu.cn)

${ }^{1}$ Jiangsu Key Laboratory of Neuropsychiatric Diseases and College of Pharmaceutical Sciences, Jiangsu Key Laboratory of Preventive and Translational Medicine for Geriatric Diseases, Soochow University, Suzhou, Jiangsu 215123, China

Edited by D. Guardavaccaro
}

regulation of apoptosis ${ }^{8}$. The transcription-independent pro-apoptotic functions of p53 are closely associated with Bcl-2 family members ${ }^{9}$, such as $\mathrm{Bcl}-2^{10}, \mathrm{Bcl}-\mathrm{X}_{\mathrm{L}}{ }^{11}$, and $\mathrm{BAX}^{5,11,12}$. The stable interaction between p53 and antiapoptotic regulators $\mathrm{Bcl}-2$ and $\mathrm{Bcl}-\mathrm{X}_{\mathrm{L}}$ is the important molecular mechanism underlying DNA damage-induced apoptosis ${ }^{13,14}$. p53 stably binds to Bcl-2 and Bcl- $\mathrm{X}_{\mathrm{L}}$, affects mitochondrial outer membrane permeabilization, and counteracts the protective role of $\mathrm{Bcl}-2$ and $\mathrm{Bcl}-\mathrm{X}_{\mathrm{L}}$ in the regulation of mitochondrion-mediated apoptosis ${ }^{10,11}$. Therefore, both the transcription-dependent and -independent functions of p53 are involved in the regulation of DNA damage-induced cell death.

Cullin 4-RING E3 ligases (CRL4s) are a group of protein complexes consisting of cullin- $4 \mathrm{~A} / \mathrm{B}$, damage-specific DNA-binding protein 1, RING finger protein, and multiple substrate receptors, which recognize a specific set of substrates for ubiquitination ${ }^{15}$. CRL4s monoubiquitinate histone $\mathrm{H} 2 \mathrm{~A}$ and regulate DNA damage repair, which is

\section{(c) The Author(s) 2019}

(c) (i) Open Access This article is licensed under a Creative Commons Attribution 4.0 International License, which permits use, sharing, adaptation, distribution and reproduction in any medium or format, as long as you give appropriate credit to the original author(s) and the source, provide a link to the Creative Commons license, and indicate if changes were made. The images or other third party material in this article are included in the article's Creative Commons license, unless indicated otherwise in a credit line to the material. If material is not included in the article's Creative Commons license and your intended use is not permitted by statutory regulation or exceeds the permitted use, you will need to obtain permission directly from the copyright holder. To view a copy of this license, visit http://creativecommons.org/licenses/by/4.0/. 
mediated by the substrate receptor DDB2 ${ }^{16}$. The substrate receptor Cdt2 promotes CRL4-mediated monoubiquitination of proliferating cell nuclear antigen in response to DNA damage ${ }^{17}$. Cereblon (CRBN), acting as a substrate receptor of the CRL4 E3 ligase, regulates a variety of cellular processes through the enzymatic function of its associated E3 ligase ${ }^{18-20}$. CRBN promotes the ubiquitination of large-conductance calcium-activated potassium $\left(\mathrm{BK}_{\mathrm{Ca}}\right)$ channel $^{20}$, chloride channel protein 1 $(\mathrm{CLC}-1)^{21}$, and presynaptic proteins ${ }^{22}$, and thus potentially regulates learning and memory ${ }^{23,24}$. The pharmacological intervention in animal models demonstrates that the learning and memory deficits in Crbn knockout (KO) mouse are affected by exaggerated AMPK activity, inhibition of mTORC1 signaling pathway ${ }^{24}$, and increased activity of $\mathrm{BK}_{\mathrm{Ca}}$ channel ${ }^{23}$. CRBN also enhances the ubiquitination and degradation of c-Jun, reduces the activity of c-Jun associated transcription factors, and thus suppresses lipopolysaccharide-induced inflammatory response $^{25}$. CRBN mediates immunomodulatory drug (IMiD)-induced death of multiple myeloma cells by promoting the ubiquitination-mediated degradation of two transcription factors IKZF1 and IKZF3 ${ }^{26,27}$. This principle has been utilized for the development of proteolysis targeting chimera in drug discovery by targeting previously "undruggable" proteins ${ }^{28,29}$. Furthermore, CRBN exhibits non-enzymatic functions independent to its associated E3 ligase in multiple processes, such as on epigenetic regulation of potassium voltage-gated channel subfamily A

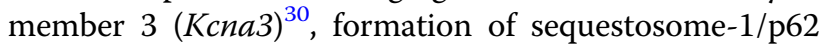
bodies $^{31}$, and inhibition of ubiquitination of tumor necrosis factor receptor-associated factor 6 and TAK1binding protein $2^{32}$ through its interaction with DNA or proteins. In addition, two CRBN mutants C391R (Cys to Arg mutation at position 391) and R419X (Arg to stop codon mutation at position 419) have been discovered to be the genetic causes for different degree of intellectual disability, indicating the important roles of CRBN in the regulation of neuronal functions ${ }^{33-35}$. Moreover, it has also been discovered that CRBN protects neuronal cells from death induced by pathogenic protein aggregates in neurodegenerative diseases ${ }^{31}$. However, it is unknown whether CRBN could regulate DNA damage in neuronal and non-neuronal cells.

In this work, through pharmacological intervention and genetic manipulation, we discovered that CRBN deficiency in cell lines, primary fibroblasts, and cortical neurons leads to their increased sensitivity to DNA-damaging reagents such as etoposide and cisplatin. Detailed studies at the molecular level revealed that CRBN protects the etoposide-induced cell death by altering the interaction between $\mathrm{p} 53$ and $\mathrm{Bcl}-2 / \mathrm{Bcl}-\mathrm{X}_{\mathrm{L}}$ through its competitive interaction with p53 but not through the enzymatic function of its associated E3 ligase. In addition, in vivo experiments showed that $\mathrm{Crbn} \mathrm{KO}$ mice exhibit increased mortality rate upon etoposide challenge. This work indicates that CRBN could protect cells from DNA damageinduced apoptosis, which provides a novel understanding of physiological roles of CRBN in p53-mediated apoptosis.

\section{Results \\ CRBN reduces DNA damage-induced apoptosis}

Although CRL4 E3 ligases regulate DNA damage response $^{36-40}$, the role of one of its substrate receptors CRBN in DNA damage response is largely unknown. To explore this function, we first determine if CRBN affects apoptosis induced by DNA damage. We cultured the primary fibroblasts dissected from wild-type (WT) and Crbn KO littermate mice (Supplementary Figure S1) and then treated them with the DNA damage inducers etoposide and cisplatin. The immunofluorescence images of propidium iodide (PI) staining showed that $\mathrm{Crbn} \mathrm{KO}$ fibroblasts are more susceptible to apoptosis induced by etoposide and cisplatin (Fig. 1a, b). Given the important role of mitochondria in DNA damage-induced apoptosis, we then examined the MMP in WT and Crbn KO fibroblasts after the induction of DNA damage. Crbn KO fibroblasts exhibited more severe MMP reduction than the WT fibroblasts, as indicated by tetramethylrhodamine methyl ester (TMRM) staining (Fig. 1c, d), which is in concert with the result obtained from PI staining. Furthermore, flow cytometry analyses showed that expression of CRBN protects cells from etoposide-induced apoptosis (Supplementary Figure S2). Taken together, our data indicate that CRBN exhibits protective roles in DNA damage-induced apoptosis.

\section{p53 is required for the regulation of CRBN on DNA damage-induced apoptosis}

Considering the critical role of p53 in DNA damageinduced apoptosis ${ }^{1}$, we examined whether p53 is involved in the CRBN-mediated protection of DNA damageinduced apoptosis. As etoposide could activate the apoptotic mitochondrial pathway followed by activation of executioner caspase-3 (Fig. 1c) ${ }^{41,42}$, we then investigated the effects of knockdown of CRBN and $p 53$ by small interfering RNA (siRNA) on the MMP. Immunoblotting experiments confirmed the knockdown efficiency of $C R B N$ and $p 53$ in human embryonic kidney (HEK) 293 cells (Fig. 2a). CRBN knockdown results in more severe reduction of MMP than the control knockdown, whereas further knocking down p53 restores MMP in HEK293 cells when exposed to etoposide (Fig. 2b, c) although MMP is not changed in the absence of etoposide (Supplementary Figure S3a). We further found that $p 53$ knockdown inhibits the caspase- 3 activation and PARP1 cleavage induced by etoposide in HEK293T cells (Fig. 2d, e and Supplementary Figure S3b). Although the protein 
a
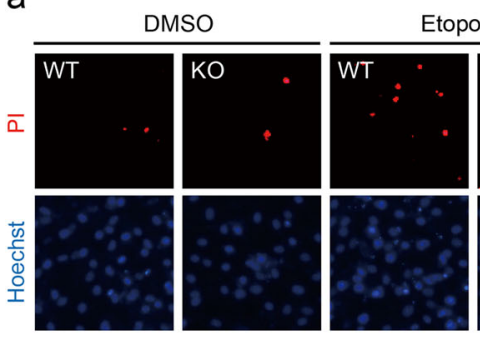

poside

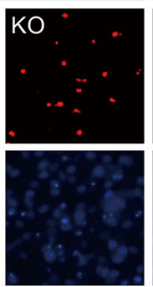

C
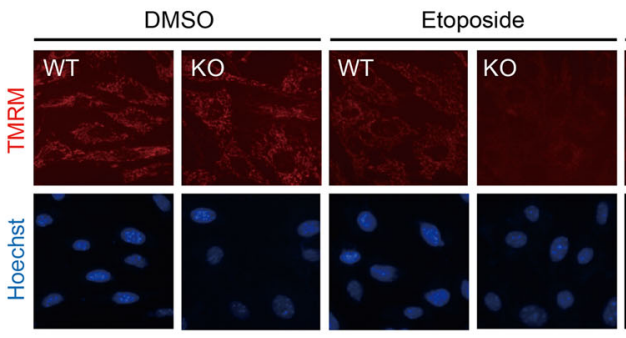
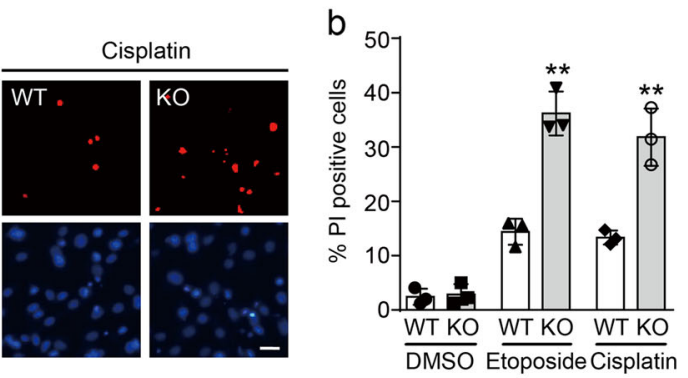

d

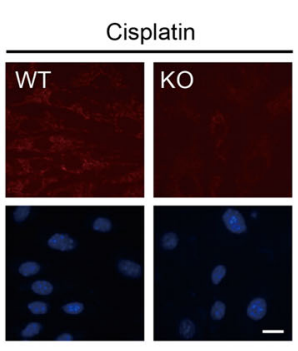

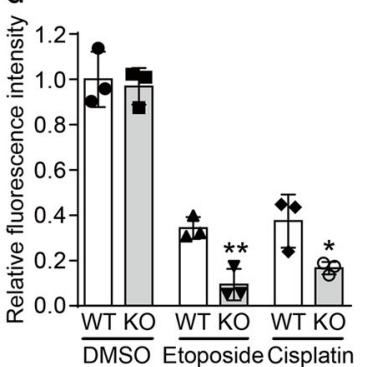

Fig. 1 Cereblon (CRBN) deficiency decreases the viability of fibroblasts upon DNA damage. a CRBN depletion increases propidium iodide (PI)-positive primary fibroblasts upon etoposide or cisplatin treatment. Primary fibroblasts from wild-type (WT) and Crbn knockout (KO) littermate mice were exposed to etoposide $(50 \mu \mathrm{M})$ or cisplatin $(10 \mu \mathrm{M})$ for $48 \mathrm{~h}$ and then subjected to Hoechst and PI staining. Scale bar: $20 \mu \mathrm{m}$. b Quantitative data (mean \pm SD) of a from three independent experiments. ${ }^{*} P<0.01$, Student's $t$-test. $\mathbf{c}$ CRBN deletion reduces the mitochondrial membrane potential of primary fibroblast cells upon etoposide or cisplatin treatment. Primary fibroblasts from WT and Crbn KO littermate mice were exposed to etoposide $(50 \mu \mathrm{M})$ or cisplatin $(10 \mu \mathrm{M})$ for $8 \mathrm{~h}$ and then subjected to tetramethylrhodamine methyl ester (TMRM) staining for microscope detection. Scale bar: $20 \mu \mathrm{m}$. d Quantitative data (mean \pm SD) of $\mathbf{c}$ from three independent experiments. ${ }^{*} P<0.05,{ }^{*} P<0.01$, Student's $t$-test

level of BAX is decreased upon p53 knockdown, CRBN does not affect the BAX protein level in the presence or absence of p53 (Fig. 2d, e). This result indicates that CRBN most probably does not regulate the p53 transcription activity. The flow cytometry analyses also demonstrated the importance of $\mathrm{p} 53$ in the CRBNmediated regulation of etoposide-induced apoptosis (Fig. 2f, g, Supplementary Figures S3c, d).

\section{CRBN directly interacts with $\mathrm{p} 53$}

Since our above experiments found that p53 is required for the CRBN-mediated regulation of etoposideinduced apoptosis, we then examined the possible interaction between CRBN and p53 by performing co-immunoprecipitation and in vitro glutathione $S$-transferase (GST)-pulldown experiments. We cotransfected Flag-p53 with green fluorescent protein (GFP) or GFP-CRBN into HEK293T cells and the cell lysates were subjected to immunoprecipitation $48 \mathrm{~h}$ after transfection. We found that GFP-CRBN but not GFP binds to Flag-p53 in HEK293T cells (Fig. 3a). The interaction between CRBN and p53 was further confirmed by performing a GST-pulldown assay (Fig. 3b), indicating their direct interaction. Co-immunoprecipitation of endogenous proteins in HEK293T cells and subsequent immunoblotting experiments revealed that CRBN interacts with p53 endogenously (Fig. 3c). To further narrow down the binding region between CRBN and p53, we constructed the CRBN and p53 truncation mutants (Fig. 3d) and performed protein interaction experiments. The results showed that the $\mathrm{N}$ terminus but not the $\mathrm{C}$ terminus of CRBN interacts with p53 (Fig. 3e), and CRBN binds to the DNA-binding domain (DBD) of p53 (Fig. 3f). Taken together, these data demonstrate that CRBN directly binds to $\mathrm{p} 53$.

CRBN is the primary target of a group of $\mathrm{IMiDs}^{19}$ including thalidomide, lenalidomide, and pomalidomide, which further promotes the interaction between CRBN and its substrates for their subsequent ubiquitination and degradation ${ }^{26,27}$. However, our experiments showed that lenalidomide and pomalidomide do not alter the interaction between CRBN and p53 (Supplementary Figure S4). This suggests that p53 might not be the ubiquitination substrate of the CRBN-associated E3 ligase. Alternatively, IMiDs might not affect the ubiquitination of p53, which is also consistent with the fact that p53 interacts with CRBN N terminus (Fig. 3e) while IMiDs interact with CRBN C terminus ${ }^{19}$ and the fact that IMiDs do not regulate the ubiquitination of a protein, which interacts with the CRBN N terminus ${ }^{43}$. Although two CRBN mutants C391R and R419X cause different degree of intellectual disability ${ }^{33,35}$, these mutations did not affect 


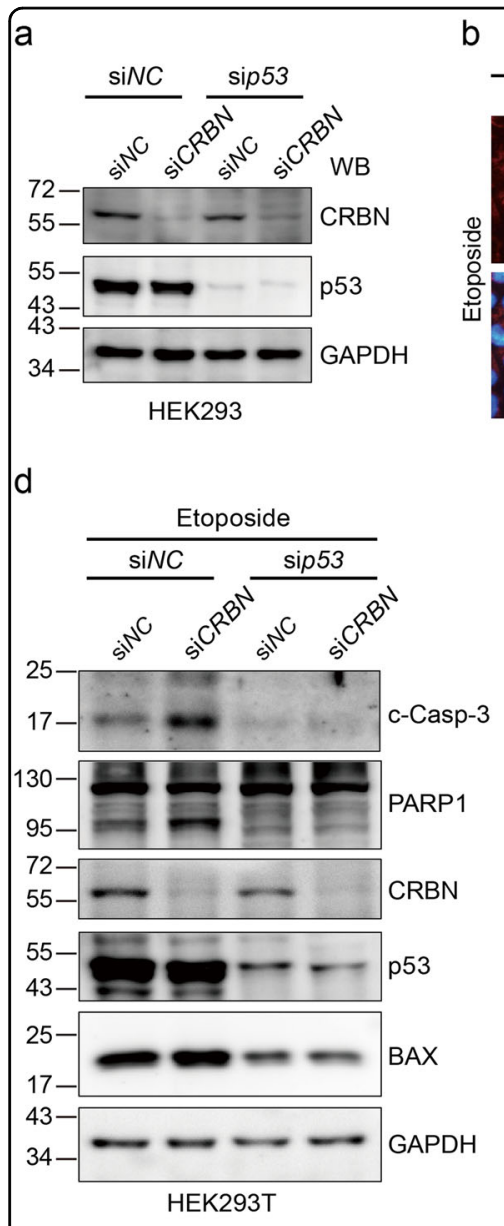

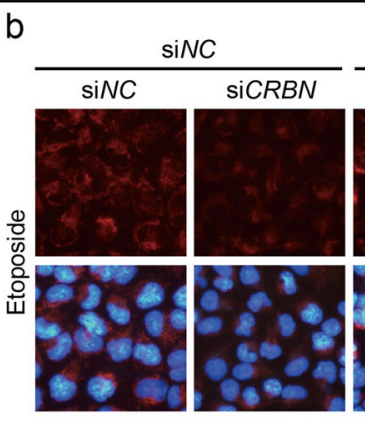
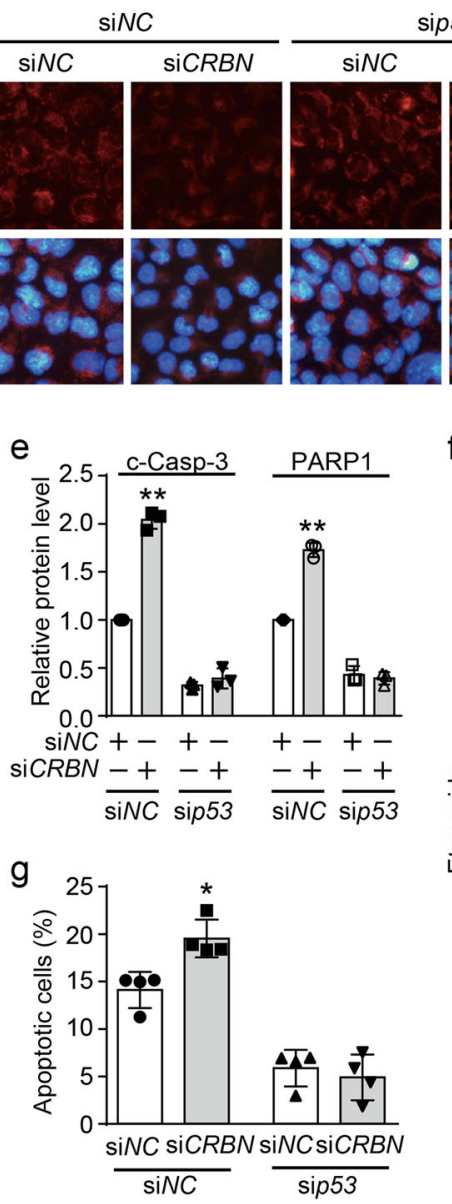

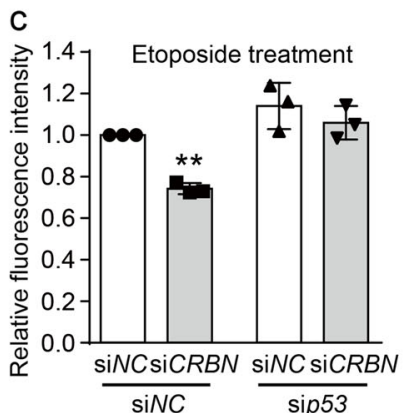

f

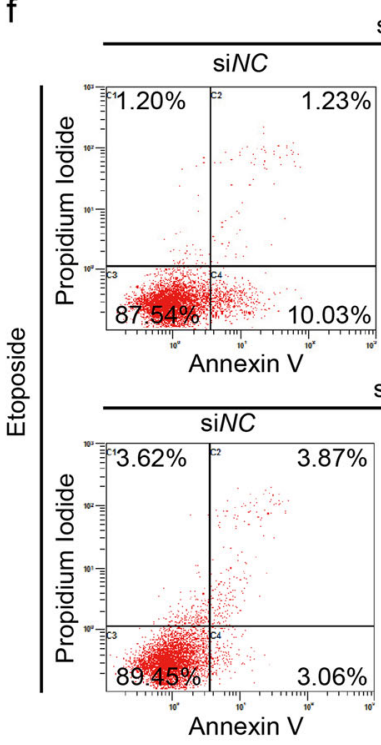

NC
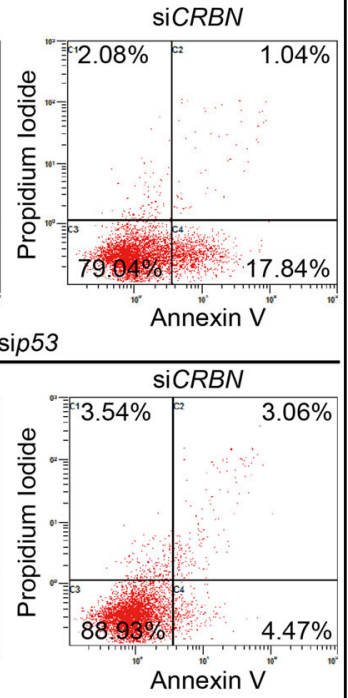

Fig. 2 Cereblon (CRBN) inhibits etoposide-induced apoptosis in a p53-dependent manner. a Validation of knockdown efficiency for CRBN and p53. Human embryonic kidney (HEK) 293 cells were transfected with siNC or siCRBN along with siNC or sip53 for $48 \mathrm{~h}$, lysed, and the resulting cell lysates were subjected to immunoblotting analysis using the indicated antibodies. $\mathbf{b}$ p53 knockdown attenuates the effect of CRBN on the mitochondrial membrane potential. HEK293 cells were transfected with siNC or siCRBN along with siNC or sip53 for $40 \mathrm{~h}$ and then treated with etoposide $(50 \mu \mathrm{M})$ for $8 \mathrm{~h}$. Cells were stained with tetramethylrhodamine methyl ester (TMRM) and visualized under fluorescence microscope. Scale bar: $20 \mu \mathrm{m}$. c Quantitative data (mean \pm SD) of b from three independent experiments. ${ }^{*} p<0.01$, Student's t-test. d p53 knockdown prevents the cleavage of caspase-3 and poly(ADP-ribose) polymerase 1 (PARP1) induced by CRBN depletion upon etoposide treatment. HEK293T cells were transfected with siNC or siCRBN along with siNC or sip53 for $24 \mathrm{~h}$ and then treated with etoposide $(50 \mu \mathrm{M})$ for $48 \mathrm{~h}$. Cells were lysed and cell lysates were subjected to immunoblotting analysis. e Quantitative data (mean \pm SD) of $\mathbf{d}$ from three independent experiments. ${ }^{* *} P<0.01$, Student's $t$-test. $\mathbf{f}$ p53 knockdown eliminates the effect of CRBN knockdown on apoptosis induced by etoposide. HEK293T cells were treated as in $\mathbf{d}$ and subjected to flow cytometry analysis. $\mathbf{g}$ Quantitative data (mean $\pm \mathrm{SD}$ ) of $\mathbf{f}$ from three independent experiments. ${ }^{*} P<0.05$, Student's $t$-test

the interaction between CRBN and p53 (Supplementary Figure S5), presumably because the mutated region is far away from p53-binding domain. This result suggests that the learning and memory deficits in those patients might not be closely linked to the p53 functions.

\section{CRBN does not affect p53 transcription activity}

Given the importance of subcellular distribution of p53 on its functions, we first investigated the possible influence of CRBN on the distribution of p53. To do so, we cotransfected GFP-p53 and mCherry-CRBN into HEK293 cells for immunofluorescence measurement. Our result showed that the nuclear localization of p53 is not influenced by CRBN under normal condition and etoposide-induced stress (Fig. 4a). In addition, two CRBN mutants do not affect the subcellular localization of p53 (Supplementary Figure S6). It has been discovered that p53 promotes cell death via its transcriptional upregulation of $B A X$, leading to the increased BAX protein level ${ }^{5}$. However, our experiments showed that the protein level of p53 and BAX is not altered upon expression of CRBN in HEK293T cells and A549 cells (Fig. 4b). Consistent results were observed in primary fibroblasts from WT and Crbn KO littermate mice (Fig. 4c). Although it has been found that CRBN could promote the ubiquitination of its binding partners such as CLC- $1^{21}$ and c-Jun ${ }^{25}$, our 


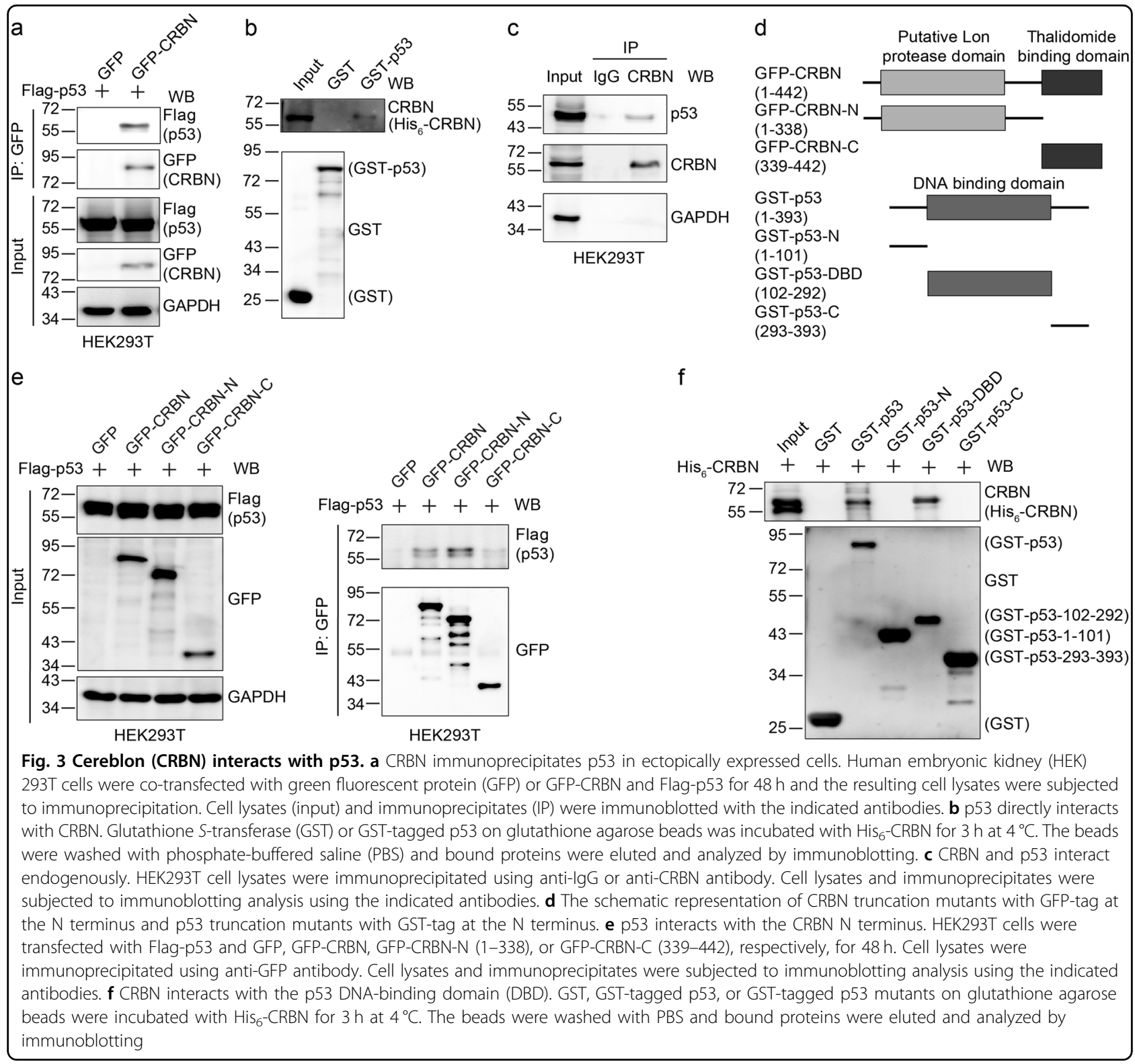

experiments did not detect the change of p53 ubiquitination upon CRBN knockdown in HEK293T cells (Fig. 4d). Taken together, these data indicate that CRBN does not regulate the subcellular localization, ubiquitination, stability, and transcription activity of p53.

\section{CRBN affects the transcription-independent function of p53}

It has been reported that p53 exhibits the transcriptionindependent function through its directly interaction with $\mathrm{Bcl}-2$ and $\mathrm{Bcl}-\mathrm{X}_{\mathrm{L}}{ }^{10,11}$. Since CRBN binds to the $\mathrm{p} 53 \mathrm{DBD}$ (Fig. 3f), which is also the binding domain for $\mathrm{Bcl}-2$ and $\mathrm{Bcl}-\mathrm{X}_{\mathrm{L}}{ }^{10,14}$, we further examined whether CRBN possibly modulates its transcription-independent function by altering the interaction between $\mathrm{p} 53$ and $\mathrm{Bcl}-2$ and
Bcl-X $\mathrm{X}_{\mathrm{L}}$. We purified GST-p53, $\mathrm{His}_{6}$-CRBN, $\mathrm{His}_{6}$-Bcl-2, and $\mathrm{His}_{6}-\mathrm{Bcl}-\mathrm{X}_{\mathrm{L}}$, which were individually expressed in Escherichia coli, and then performed GST-pulldown assay in vitro. The result indicates that p53 directly interacts with $\mathrm{Bcl}-2$, but the interaction of p53 with $\mathrm{Bcl}-2$ is decreased in the presence of CRBN (Fig. 5a). A similar result was also observed for $\mathrm{Bcl}-\mathrm{X}_{\mathrm{L}}$ (Fig. $5 \mathrm{~b}$ ). Furthermore, the interaction of p53 with Bcl-2 or Bcl- $\mathrm{X}_{\mathrm{L}}$ is increased when we knocked down $C R B N$ in HEK293T cells using the CRBN-specific siRNAs (Fig. 5c, d), and gradually decreased when we overexpressed increasing amount of CRBN in HEK293T cells (Fig. 5e, f). Together, our results demonstrated that CRBN affects the transcriptionindependent function of p53 by directly suppressing the interaction between p53 and $\mathrm{Bcl}-2 / \mathrm{Bcl}-\mathrm{X}_{\mathrm{L}}$. 


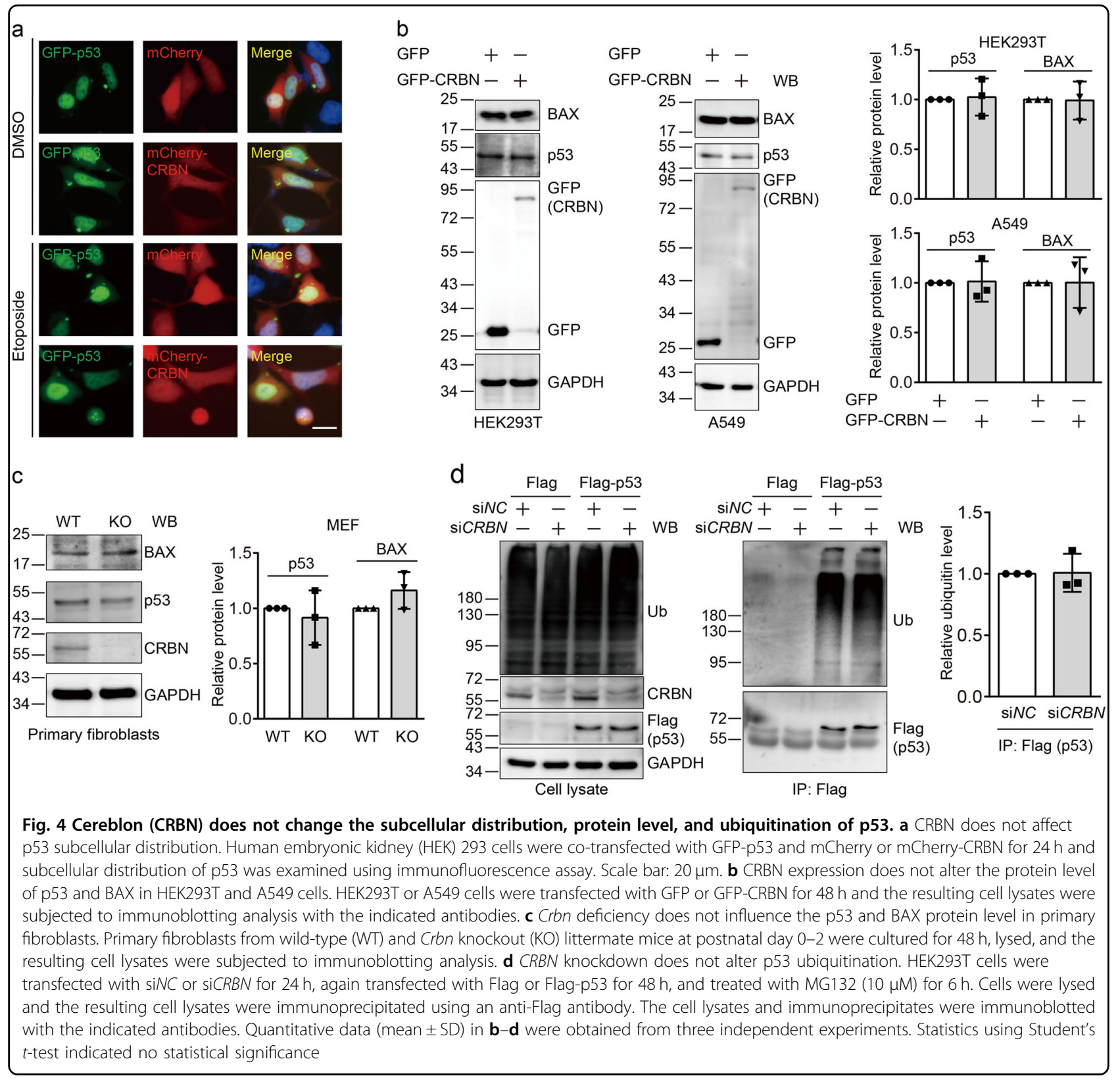

\section{Crbn KO mice exhibit a higher mortality rate following etoposide challenge}

Our results showed that CRBN affects the transcriptionindependent function of p53 and modulates the DNA damage-induced apoptosis. We then examined whether the mortality rate of mice is affected by $\mathrm{Crbn} \mathrm{KO}$ upon etoposide challenge. The survival rate was monitored over 4 days after WT and Crbn KO mice were challenged with etoposide (100 mg/kg, intraperitoneal injection). All Crbn KO mice received etoposide $(100 \mathrm{mg} / \mathrm{kg})$ died within 4 days of injection whereas $50 \%$ of WT mice survived 4 days after injection (Fig. 6a), which is consistent with the previous study that the median lethal dose of etoposide for mice is about $100 \mathrm{mg} / \mathrm{kg}^{44}$. Because the central nervous system is susceptible to DNA damage-induced apoptosis $^{45,46}$, we cultured cortical neurons obtained from WT and Crbn KO littermate mice and treated them with etoposide. The data showed that Crbn KO cortical neurons are more sensitive to etoposide than WT cortical neurons (Fig. 6b and Supplementary Figure S7). Immunoblotting of brain tissues showed that there is much more cleaved caspase-3 in Crbn KO mice than in WT mice following etoposide challenge (Fig. 6c). Protein interaction analyses using these brain lysates further showed that more Bcl-2 and Bcl- $\mathrm{X}_{\mathrm{L}}$ bind to p53 in Crbn $\mathrm{KO}$ mice than in WT mice (Fig. 6d), confirming the 


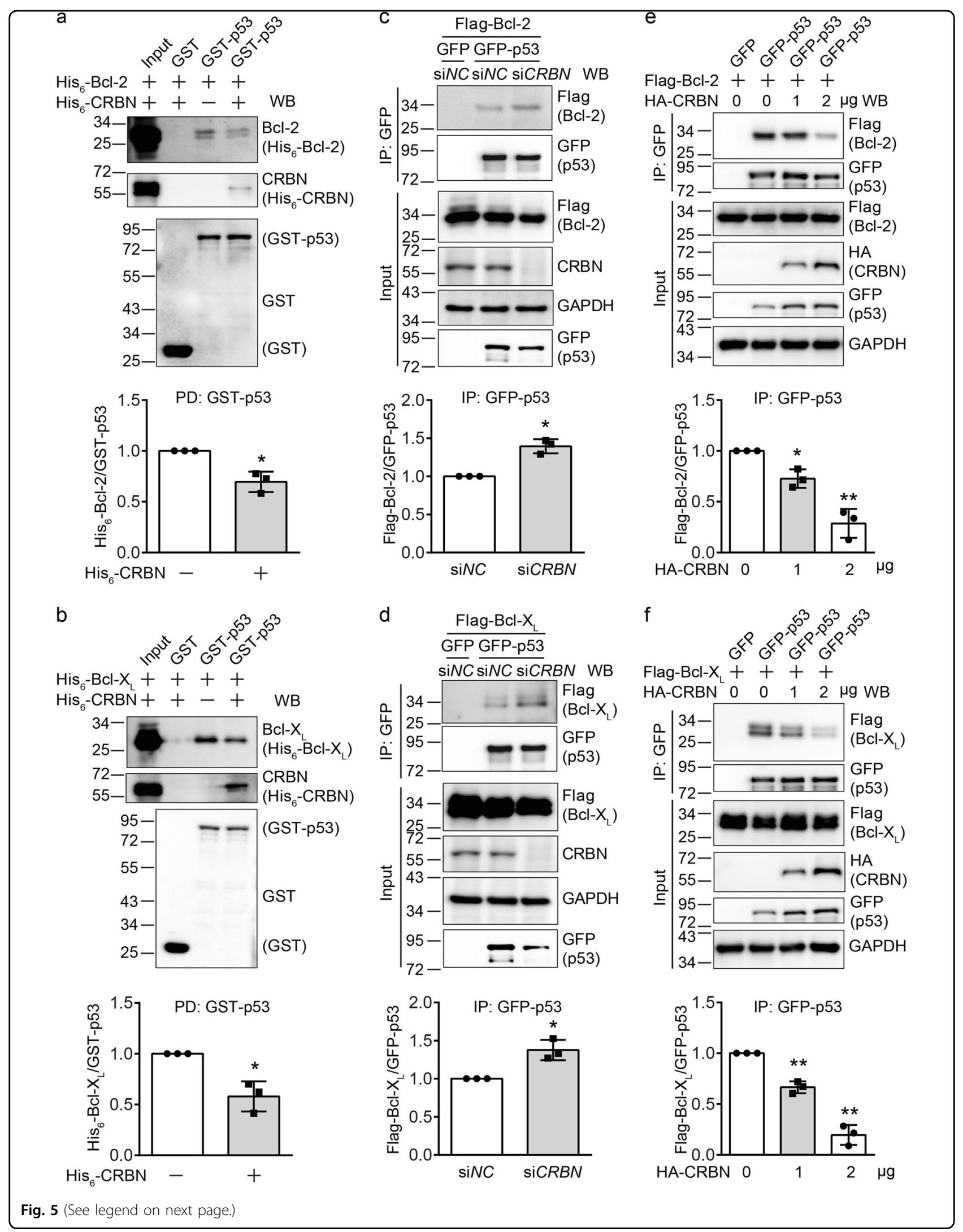


(see figure on previous page)

Fig. 5 Cereblon (CRBN) attenuates the interaction between $\mathbf{p} 53$ and $\mathbf{B c l}-\mathbf{2}$ or $\mathbf{B c l}-\mathbf{X}_{\mathbf{L}} \cdot \mathbf{a}, \mathbf{b} C R B N$ reduces the interaction between p53 and BCl-2 (a) or $\mathrm{BCl}-\mathrm{X}_{\mathrm{L}}$ (b) in vitro. Glutathione agarose beads with purified glutathione S-transferase (GST) or GST-p53 were incubated with His ${ }_{6}-\mathrm{BCl}-2$ (a) or $\mathrm{His}_{6}-\mathrm{BCl}-\mathrm{X}_{\mathrm{L}}(\mathbf{b})$ in the absence or presence of $\mathrm{His}_{6}-\mathrm{CRBN}$ at $4^{\circ} \mathrm{C}$ for $3 \mathrm{~h}$. The agarose beads were washed with phosphate-buffered saline and bound proteins were eluted and subjected to immunoblotting analysis using the indicated antibodies. $\mathbf{c}, \mathbf{d}$ CRBN knockdown enhances the interaction between p53 and BCl-2 (c) or BCl- $X_{\mathrm{L}}$ (d). Human embryonic kidney (HEK) 293T cells were first transfected with siNC or siCRBN for $24 \mathrm{~h}$ and then cotransfected again with GFP or GFP-p53 and Flag-Bcl-2 (c) or Flag-BCl-X $(\mathbf{d})$ for $48 \mathrm{~h}$. Cells were lysed and the resulting cell lysates were

immunoprecipitated with an anti-GFP antibody. Cell lysates and immunoprecipitates were subjected to immunoblotting analysis using the indicated antibodies. e, $\mathbf{f} C R B N$ reduces the interaction between $\mathrm{p} 53$ and $\mathrm{BCl}-2$ (e) or BCl- $\mathrm{X}_{\mathrm{L}}(\mathbf{f})$ in HEK293T cells. Flag-BCl-2 or Flag-BCl- $\mathrm{X}_{\mathrm{L}}$ was co-transfected into HEK293T cells in 6-cm plates with GFP or GFP-p53 in the absence or in the presence of increasing amounts of HA-CRBN $(0,1$, and $2 \mu \mathrm{g})$. The cell lysates were immunoprecipitated with an anti-GFP antibody, and then the cell lysates and immunoprecipitates were subjected to immunoblotting analysis using the indicated antibodies. Quantitative data (mean \pm SD) in a-f were from three independent experiments. Student's $t$-test: ${ }^{*} P<0.05$, **P $<0.01$

physiological role of CRBN on the interaction between p53 and Bcl-2/Bcl- $\mathrm{X}_{\mathrm{L}}$. Taken together, these data indicate that CRBN inhibits DNA damage-induced apoptosis by controlling the transcription-independent function of p53 (Fig. 6e).

\section{Discussion}

It has been found that multiple CRL4 E3 ligase complexes regulate DNA damage-induced apoptosis ${ }^{36-40}$. The functions of one of their substrate receptors CRBN in DNA damage response remain elusive ${ }^{37}$ although this protein has been utilized for targeted protein degradation in potential cancer therapy. In this study, we found that primary fibroblasts and cortical neurons from $\mathrm{Crbn} \mathrm{KO}$ mice are more sensitive to etoposide than those from their WT littermate mice (Figs. 1 and $6 \mathrm{~b}$ ), which suggests that CRBN protects DNA damage-induced apoptosis in vitro. In vivo experiments also showed that $\mathrm{Crbn} \mathrm{KO}$ mice are more susceptible to etoposide challenge, evidenced by the fact that KO mice exhibit higher mortality rate than WT mice (Fig. 6a). Taken together, our results demonstrated that CRBN is involved in the regulation of DNA damageinduced apoptosis in vitro and in vivo.

p53 plays critical roles in DNA damage-induced apoptosis $^{1,2}$. However, the molecular mechanisms by which p53 regulates DNA damage-induced apoptosis are not completely elucidated ${ }^{42,47}$. Several studies indicated that both the transcriptional function and transcriptionindependent function of p53 are involved in DNA damage-induced apoptosis ${ }^{41,42,48,49}$. It has been discovered that CRBN is required for the anti-myeloma activity of IMiDs ${ }^{19,50}$ but IMiDs cannot improve the overall survival of multiple myeloma patients with p53 deficiency $^{51}$, indicating the possible molecular linkage between CRBN and p53. In this study, we demonstrated that the regulation of DNA damage-induced apoptosis by CRBN depends on p53 (Fig. 2). Although CRBN functions as a substrate receptor of the CRL4 E3 ligase and mediates the degradation of many substrates, it does not affect the ubiquitination and protein level of p53 and thus BAX protein level, indicating that CRBN does not regulate the ubiquitin-mediated degradation of p53 (Fig. 4) and its transcriptional function. Instead, the GST-pulldown and co-immunoprecipitation experiments discovered that CRBN expression decreases while CRBN knockdown enhances the interaction of p53 with $\mathrm{Bcl}-2$ and $\mathrm{Bcl}-\mathrm{X}_{\mathrm{L}}$ through its competitive interaction with $\mathrm{p} 53$, indicating that CRBN modulates the transcription-independent function of p53 (Fig. 5). In short, this work revealed a novel mechanism for CRBN in the regulation of DNA damage-induced apoptosis. This provides another example where CRBN plays regulatory functions not associated with the enzymatic activity of CRL4 ${ }^{\mathrm{CRBN}}$ E3 ligase.

CRBN is the primary target of IMiDs and promotes the ubiquitination and degradation of two transcription factors IKZF1 and IKZF3 in the presence of IMiDs ${ }^{19,26,27}$. Through this mechanism, IMiDs exhibit their anti-myeloma activity. Although CRBN knockdown initially induces myeloma cell cytotoxicity $^{50,52}$, CRBN protein level is decreased in IMiDresistant myeloma cells ${ }^{50,53}$. Here we found that CRBN deficiency does not alter the apoptosis of primary fibroblasts and primary cortical neurons and the mortality rate of mice under normal condition although Crbn-deficient mice exhibit aberration on learning and memory ${ }^{54}$. However, under DNA damage stress, CRBN deficiency increases apoptosis of cell lines and primary cells.

Two CRBN mutants C391R and R419X have been discovered in children with different degree of intellectual disability $^{33,35}$ although the exact molecular mechanism for the cause of this disease is unknown. It has been discovered that many proteins associated with intellectual disability are also involved in cellular response to DNA damage ${ }^{55,56}$. Despite the fact that the two ectopically expressed CRBN mutants bind to p53 to a degree similar to the WT CRBN, we cannot completely rule out the possible influence of p53 on the deficits of neuronal development and intellectual disability by CRBN mutation under stress since it has been shown that at least one of the mutants has reduced stability ${ }^{34}$. Autophagy is extensively involved in neuronal injury and death ${ }^{57-59}$. 


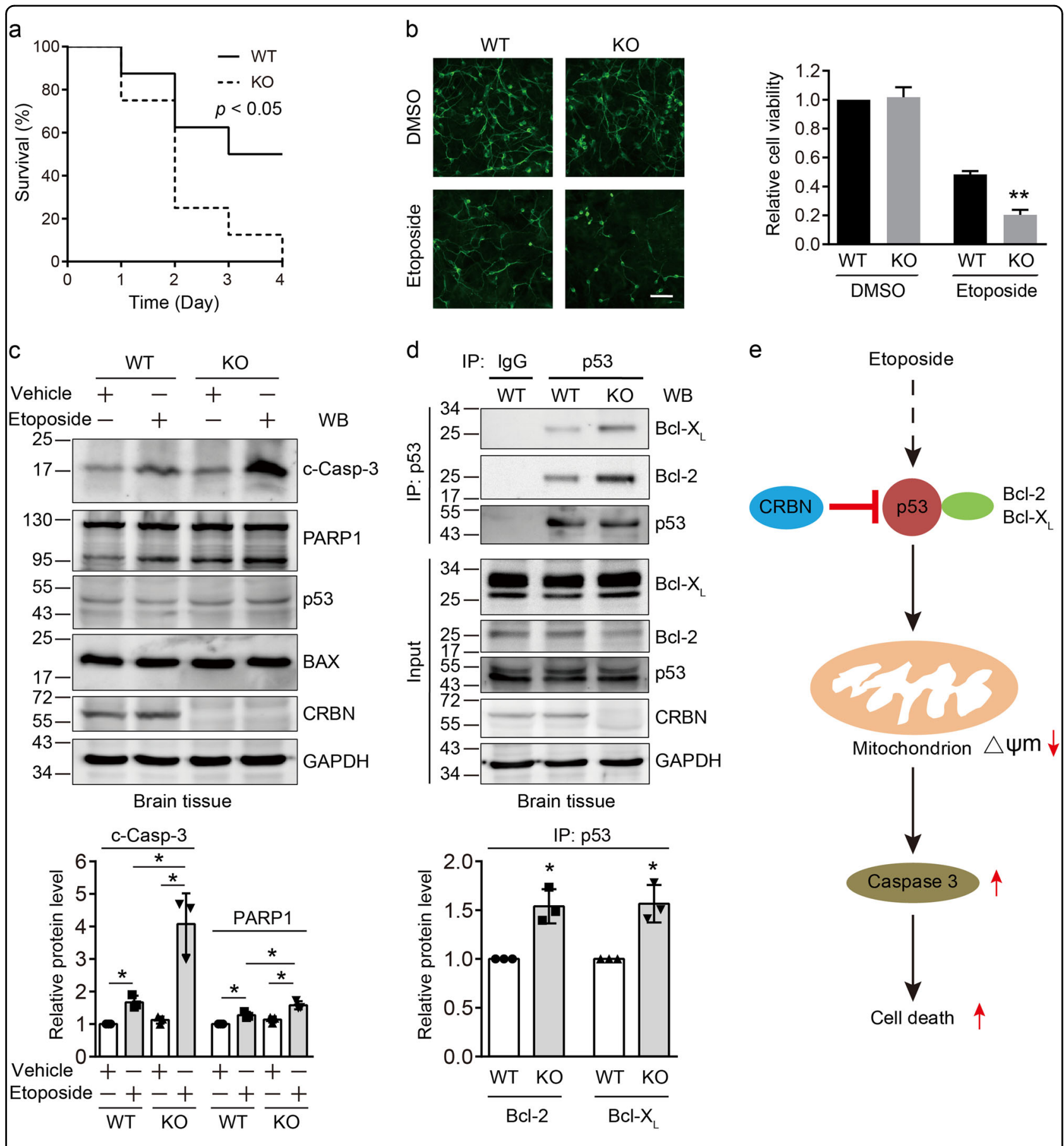

Fig. 6 (See legend on next page.)

Although CRBN does not affect the autophagy under physiological condition ${ }^{31}$, it requires further investigation to determine whether CRBN modulates the p53-related autophagy in neurons upon DNA damage ${ }^{60}$.

In conclusion, we discovered a new function for CRBN in the regulation of DNA damage-induced apoptosis after etoposide and cisplatin treatment and revealed the underlying molecular mechanism. In this mechanism, CRBN does not regulate the ubiquitin-mediated degradation of p53 and the protein level of its downstream apoptotic regulator BAX. However, the interaction between CRBN and p53 attenuates the transcription-independent function of $\mathrm{p} 53$ by 


\begin{abstract}
(see figure on previous page)
Fig. 6 Crbn deficiency elevates the mortality rate of mice upon etoposide challenge. a Crbn deficiency promotes the death of mice after etoposide injection. Wild-type (WT) $(n=8)$ and Crbn knockout $(K O)(n=8)$ mice were intraperitoneally injected with $100 \mathrm{mg} / \mathrm{kg}$ etoposide. Mice were monitored for 4 days. ${ }^{*} P<0.05$, log-rank (Mantel-cox) test. $\mathbf{b}$ Crbn $\mathrm{KO}$ reduces the viability of cortical neurons upon etoposide treatment. Primary cortical neurons from WT and Crbn KO littermate mice were treated with etoposide (5 $\mu \mathrm{M})$ for $24 \mathrm{~h}$ and then subjected to immunofluorescence assay using the neuron-specific marker MAP2 to count the survival neurons. Scale bar: $50 \mu \mathrm{m}$. c Crbn KO promotes caspase-3 and poly(ADP-ribose) polymerase 1 (PARP1) cleavage in mouse brain tissues upon etoposide treatment. WT and Crbn KO littermate mice were subjected to intraperitoneal injection with $100 \mathrm{mg} / \mathrm{kg}$ etoposide or vehicle [30\% propylene glycol, 5\% Tween 80, and 65\% D5W (5\% dextrose in water)] for $24 \mathrm{~h}$ and then the brain tissues were dissected out and subjected to immunoblotting analysis using the indicated antibodies. $\mathbf{d}$ Crbn KO enhances the interaction between p53 and Bcl-2 or BCl- $\mathrm{X}_{\mathrm{L}}$ in brain tissues. WT and Crbn KO littermate mice were subjected to intraperitoneal injection with $100 \mathrm{mg} / \mathrm{kg}$ etoposide for $24 \mathrm{~h}$ and then the brain tissues were collected, lysed, and subjected to immunoprecipitation using an anti-lgG or anti-p53 antibody. The cell lysates and immunoprecipitates were immunoblotted with the indicated antibodies. Quantitative data (mean \pm SD) in $\mathbf{b}$ - $\mathbf{d}$ were obtained from three independent experiments. Statistics: Student's $t$-test, ${ }^{*} P<0.05,{ }^{* *} P<0.01$. e Proposed model for the regulation of cereblon (CRBN) on the etoposide-induced apoptosis. $\mathrm{p} 53$ binds to $\mathrm{BCl}-2$ and $\mathrm{BCl}-\mathrm{X}_{\mathrm{L}}$, which reduces mitochondrial membrane potential $(\Delta \psi \mathrm{m})$ after etoposide treatment, leads to the enhanced cleavage of caspase-3 and PARP1, and results in apoptosis. CRBN attenuates the interaction between p53 and BCl-2/BCl- $\mathrm{X}_{\mathrm{L}}$ by its competitive interaction with p53 and thus reduces the mitochondrion-induced cell death
\end{abstract}

decreasing the interaction of p53 with $\mathrm{Bcl}-2$ and $\mathrm{Bcl}-\mathrm{X}_{\mathrm{L}}$, thus protecting cells from DNA damage-induced apoptosis. This work would extend our understanding of the role of CRBN on DNA damage response and demonstrate the protective roles of CRBN under stress.

\section{Materials and methods \\ Animals}

Crbn KO mice were provided by Dr. Yong Cang at Zhejiang University (China) and bred in the animal facility at Soochow University. For in vivo drug treatment, etoposide was dissolved in a buffer containing $30 \%$ propylene glycol, 5\% Tween 80, and 65\% D5W (5\% dextrose in water) and intraperitoneally administered to the WT and $\mathrm{Crbn} \mathrm{KO}$ mice at a dose of $100 \mathrm{mg} / \mathrm{kg}$. Mice were checked every $24 \mathrm{~h}$ to determine their survival. All animal study protocols were approved by the Institutional Animal Care and Use Committee of Soochow University.

\section{Plasmids}

Plasmids expressing GFP-p53, GST-p53, Flag-p53, FlagBcl- $\mathrm{X}_{\mathrm{L}}, \mathrm{His}_{6}-\mathrm{Bcl}-\mathrm{X}_{\mathrm{L}}$, Flag-Bcl-2, $\mathrm{His}_{6}-\mathrm{Bcl}-2, \mathrm{His}_{6}-\mathrm{CRBN}$, GFP-CRBN, GFP-CRBN-N (1-388), and GFP-CRBN-C (339-442) were obtained from previous work ${ }^{31,61-63} \cdot \mathrm{p} 53$ cDNA was amplified from the Flag-p53 plasmid and subsequently inserted into PA-mCherry-C1 vector at XhoI/BamHI sites to obtain mCherry-p53 plasmid. The primers used for PCR were CCGCTCGAGAAATGGAG GAGCCGCAGTC (sense) and CGCGGATCCTCAGTC TGAGTCAGG (antisense) from GeneWiz (Suzhou, Jiangsu, China).

\section{Cell culture and transfection}

HEK293 and 293T cells and primary dermal fibroblasts were grown in Dulbecco's modified Eagle's medium (DMEM) (HyClone, Logan, UT, USA) containing 10\% fetal bovine serum (FBS, Lonsera, Lonsa Science SRL, Uruguay), 100 units $/ \mathrm{mL}$ penicillin, and $100 \mu \mathrm{g} / \mathrm{mL}$ streptomycin (Gibco, Grand Island, NY, USA). Lipofectamine 3000
(Invitrogen, Carlsbad, CA, USA) was used to transfect plasmids and RNAiMAX (Invitrogen) was used to transfect siRNAs in HEK293 and 293T cells. All siRNAs and a negative control (siNC: UUCUCCGAACGUGUCACGU dTdT) were purchased from GenePharma (Shanghai, China). The sequences were: sip53, sense: GACUCCAG UGGUAAUCUACU, antisense: AGUAGAUUACCACU GGAGUC; siCRBN, sense: CCCAGACACUGAAGAU GAAAU, antisense: AUUUCAUCUUCAGUGUCUGGG.

\section{Primary cultures of dermal fibroblasts and cortical neurons}

Primary dermal fibroblasts were dissected from mice at postnatal day $0-2$ and cultured according to a method described previously ${ }^{31}$. Briefly, head, tail, and limbs of mice were amputated with surgical scissors. Viscera were discarded and skin was put in pre-chilled Hanks balanced salt solution. Tissue was cut into $\sim 1 \mathrm{~mm}$ pieces and digested at $37^{\circ} \mathrm{C}$ for $20 \mathrm{~min}$ with $0.25 \%$ trypsin solution (Gibco). Cells were collected after centrifugation and resuspended in DMEM containing 10\% FBS, 100 units/ $\mathrm{mL}$ penicillin, and $100 \mu \mathrm{g} / \mathrm{mL}$ streptomycin.

Cortical tissues from neonatal mice at postnatal day 0-2 were dissected and digested with $0.25 \%$ trypsin solution to obtain individual cells. Cells were plated at 800,000 cells/ well in 24-well plates coated with poly-D-lysine (Sigma, St. Louis, MO, USA) with neurobasal plating medium containing 2\% FBS, 2\% B27 supplements (Gibco), and $2 \mathrm{mM}$ L-glutamine (Gibco). Neurobasal culture medium containing $2 \%$ B27 supplements and $2 \mathrm{mM}$ L-glutamine was used to replace half of the medium every other day.

\section{PI and TMRM staining}

Primary dermal fibroblasts, primary cortical neurons, and HEK293 cells were cultured and treated with dimethyl sulfoxide, etoposide (Selleck, Houston, TX, USA), or cisplatin (Selleck). Cells were incubated with Hoechst (Sigma) and PI (Beyotime, Haimen, Jiangsu, China) for 5 min, washed with phosphate-buffered saline (PBS), and detected under a fluorescence microscope. 
TMRM staining was carried out according to a previous procedure to measure the mitochondrial membrane potential $^{64}$. Briefly, cells were treated with $100 \mathrm{nM}$ TMRM (Sigma) at $37^{\circ} \mathrm{C}$ for $15 \mathrm{~min}$, washed with PBS, and detected under a fluorescence microscope.

\section{Immunoprecipitation}

HEK293T cells or tissues for mice were lysed with RIPA lysis buffer [ $25 \mathrm{mM}$ Tris- $\mathrm{HCl}$ ( $\mathrm{pH} 7.6), 150 \mathrm{mM}$ $\mathrm{NaCl}, 1 \% \mathrm{NP}-40,1 \%$ sodium deoxycholate, and protease inhibitor cocktail (Roche, Basel, Switzerland)]. Immunoprecipitation was carried out using a previous method $^{65}$. The rabbit polyclonal anti-GFP antibodies, rabbit or mouse IgG (Beyotime), or mouse monoclonal anti-p53 antibodies (Santa Cruz Biotechnology, Santa Cruz, CA, USA) were incubated with protein G sepharose beads (Roche) for 3-6 $\mathrm{h}$ and then incubated with cell lysates for $8-12 \mathrm{~h}$ at $4{ }^{\circ} \mathrm{C}$. The protein $\mathrm{G}$ sepharose beads were washed six times with RIPA lysis buffer and subjected to heating with $2 \times$ SDS sample loading buffer. The eluted proteins were immunoblotted with the indicated antibodies.

\section{In vitro pulldown assay}

GST-pulldown assay was performed according to a method described previously ${ }^{66}$. All tagged proteins used here were expressed in E. coli. Briefly, $30 \mu \mathrm{L}$ of glutathione agarose beads (Amersham Pharmacia Biotech, Piscataway, NJ, USA) were incubated with GST or GST-tagged proteins for $30-60 \mathrm{~min}$ at $4{ }^{\circ} \mathrm{C}$ and washed three times with pre-chilled PBS. Beads were further incubated with $\mathrm{His}_{6}{ }^{-}$ tagged CRBN alone or with Bcl-2 or Bcl- $\mathrm{X}_{\mathrm{L}}$ for $3 \mathrm{~h}$ at $4{ }^{\circ} \mathrm{C}$ and again washed five times with pre-chilled PBS. GSTtagged proteins were eluted with $2 \times$ SDS sample loading buffer for immunoblotting analysis.

\section{Immunoblotting}

Proteins were separated by SDS-polyacrylamide gel electrophoresis, transferred to polyvinylidene difluoride membrane (Millipore, Bedford, MA, USA), and immunoblotted according to a previous procedure ${ }^{67}$. The following primary antibodies were used for immunoblotting: Flag (Sigma), GFP (Santa Cruz Biotechnology), GAPDH (HuaAn Biotechnology, Hangzhou, Zhejiang, China), rabbit Bcl-2 (Epitomics, Burlingame, CA, USA), rabbit Bcl- $\mathrm{X}_{\mathrm{L}}$ (Cell Signaling Technology, Danvers, MA, USA), mouse CRBN (from Xiu-Bao Chang, Mayo Clinic College of Medicine, USA), rabbit CRBN (ProteinTech, Rosemont, IL, USA), and anti-mouse IgG-horseradish peroxidase (HRP) or anti-rabbit IgG-HRP sheep antibodies (Amersham Pharmacia Biotech). Proteins were visualized using western blotting chemiluminescent horseradish peroxidase substrate (NCM Biotech, Suzhou, Jiangsu, China).

\section{Immunocytochemistry assay}

First, primary cortical neurons or HEK293 cells were washed twice with PBS and fixed with $4 \%$ paraformaldehyde for 5-10 $\mathrm{min}$ at room temperature. Second, cells were permeabilized with $0.25 \%$ Triton X-100 at room temperature for $5 \mathrm{~min}$ and blocked with 5\% FBS at room temperature for $1 \mathrm{~h}$. Then, neuronal cells were incubated with microtubule-associated protein 2 antibody (Santa Cruz Biotechnology) at room temperature for $2-3 \mathrm{~h}$ and incubated with the Alexa Fluor 488 (green)-conjugated fluorescent secondary antibodies (Invitrogen) for $1 \mathrm{~h}$. The cells were stained with Hoechst and visualized under an inverted microscope (IX71, Olympus, Tokyo, Japan).

\section{Data analysis}

Photoshop 7.0 (Adobe Systems, San Jose, CA, USA) was used to analyze the densitometry of fluorescence and chemiluminescence from three independent experiments and the final data were analyzed using GraphPad Prism (GraphPad Software, La Jolla, CA, USA). P-values were calculated using Student's $t$-test.

\section{Acknowledgements \\ We are grateful to Dr. Guanghui Wang at Soochow University (China) for generously providing plasmids ( $\mathrm{p} 53, \mathrm{BCl}-2$, and $\mathrm{BCl}-\mathrm{X}_{\mathrm{L}}$ ), to Dr. Yong Cang at Zhejiang University (China) for Crbn KO mice, and to Dr. Xiu-Bao Chang at Mayo Clinic College of Medicine (USA) for the mouse CRBN antibody. This work was supported by the National Natural Science Foundation of China (81703535 and 31670833), National Key R\&D Program of China \\ (2018YFC1705500), China Postdoctoral Science Foundation (2017M611895), Natural Science Foundation of Jiangsu Higher Education Institutions of China (17KJD180005), Jiangsu Province Postdoctoral Science Foundation (1701130C), National Center for International Research (2017B01012), Jiangsu Key \\ Laboratory of Neuropsychiatric Diseases (BM2013003), a project funded by the Priority Academic Program Development (PAPD) of Jiangsu Higher Education Institutions.}

Conflict of interest

The authors declare that they have no conflict of interest.

\section{Publisher's note}

Springer Nature remains neutral with regard to jurisdictional claims in published maps and institutional affiliations.

Supplementary Information accompanies this paper at (https://doi.org/ 10.1038/s41419-019-1317-7).

Received: 17 August 2018 Revised: 18 December 2018 Accepted: 20 December 2018

Published online: 25 January 2019

\section{References}

1. Roos, W. P. \& Kaina, B. DNA damage-induced cell death by apoptosis. Trends Mol. Med. 12, 440-450 (2006).

2. Caelles, C., Helmberg, A. \& Karin, M. p53-Dependent apoptosis in the absence of transcriptional activation of p53-target genes. Nature 370, 220-223 (1994).

3. Chipuk, J. E. \& Green, D. R. Dissecting p53-dependent apoptosis. Cell Death Differ. 13, 994-1002 (2006)

4. Amaral, J. D., Xavier, J. M., Steer, C. J. \& Rodrigues, C. M. The role of p53 in apoptosis. Discov. Med. 9, 145-152 (2010). 
5. Toshiyuki, M. \& Reed, J. C. Tumor suppressor p53 is a direct transcriptional activator of the human bax gene. Cell 80, 293-299 (1995).

6. Nakano, K. \& Vousden, K. H. PUMA, a novel proapoptotic gene, is induced by p53. Mol. Cell 7, 683-694 (2001).

7. Elmore, S. Apoptosis: a review of programmed cell death. Toxicol. Pathol. 35, 495-516 (2007)

8. Haupt, Y., Rowan, S., Shaulian, E., Vousden, K. H. \& Oren, M. Induction of apoptosis in HeLa cells by trans-activation-deficient p53. Gene Dev. 9, 2170-2183 (1995).

9. Hemann, M. T. \& Lowe, S. W. The p53-Bcl-2 connection. Cell Death Differ. 13, 1256-1259 (2006)

10. Tomita, Y. et al. WTp53, but not tumor-derived mutants, bind to $\mathrm{BCl} 2$ via the DNA binding domain and induce mitochondrial permeabilization. J. Biol. Chem. 281, 8600-8606 (2006).

11. Mihara, M. et al. p53 has a direct apoptogenic role at the mitochondria. Mol. Cell 11, 577-590 (2003).

12. Wolff, S., Erster, S., Palacios, G. \& Moll, U. M. p53's mitochondrial translocation and MOMP action is independent of Puma and Bax and severely disrupts mitochondrial membrane integrity. Cell Res. 18, 733-744 (2008).

13. Han, J., Goldstein, L. A., Hou, W., Gastman, B. R. \& Rabinowich, H. Regulation of mitochondrial apoptotic events by p53-mediated disruption of complexes between antiapoptotic BCl-2 members and Bim. J. Biol. Chem. 285, 22473-22483 (2010).

14. Green, D. R. \& Kroemer, G. Cytoplasmic functions of the tumor suppressor p53. Nature 458, 1127 (2009).

15. Jackson, S. \& Xiong, Y. CRL4s: the CUL4-RING E3 ubiquitin ligases. Trends Biochem. Sci. 34, 562-570 (2009).

16. Kapetanaki, M. G. et al. The DDB1-CUL4A ${ }^{\mathrm{DDB} 2}$ ubiquitin ligase is deficient in xeroderma pigmentosum group $\mathrm{E}$ and targets histone $\mathrm{H} 2 \mathrm{~A}$ at UV-damaged DNA sites. Proc. Natl Acad. Sci. USA 103, 2588-2593 (2006).

17. Terai, K. Abbas, T., Jazaeri, A. A. \& Dutta, A. CRL4 ${ }^{\text {Cdt2 }}$ E3 ubiquitin ligase monoubiquitinates PCNA to promote translesion DNA synthesis. Mol. Cell 37, 143-149 (2010).

18. Angers, $\mathrm{S}$. et al. Molecular architecture and assembly of the DDB1-CUL4A ubiquitin ligase machinery. Nature 443, 590-593 (2006).

19. Ito, T. et al. Identification of a primary target of thalidomide teratogenicity. Science 327, 1345-1350 (2010).

20. Liu, J. et al. CRLAA ${ }^{\text {CRBN }}$ E3 ubiquitin ligase restricts BK channel activity and prevents epileptogenesis. Nat. Commun. 5, 3924 (2014).

21. Chen, Y.-A. et al. The cullin 4A/B-DDB1-cereblon E3 ubiquitin ligase complex mediates the degradation of CLC-1 chloride channels. Sci. Rep. 5, 10667 (2015).

22. Del Prete, D., Rice, R. C., Rajadhyaksha, A. M. \& D'Adamio, L. Amyloid precursor protein (APP) may act as a substrate and a recognition unit for CRL4 ${ }^{\text {CRBN }}$ and Stub1 E3 ligases facilitating ubiquitination of proteins involved in presynaptic functions and neurodegeneration. J. Biol. Chem. 291, 17209-17227 (2016).

23. Song, $\mathrm{T}$. et al. CRL4 antagonizes $\mathrm{SCF}^{\mathrm{FbxO}}{ }^{\mathrm{F}}$-mediated turnover of cereblon and BK channel to regulate learning and memory. PLoS Genet. 14, e1007165 (2018).

24. Bavley, C. C. et al. Rescue of learning and memory deficits in the human nonsyndromic intellectual disability cereblon knock-out mouse model by targeting the AMP-activated protein kinase-mTORC1 translational pathway. J. Neurosci. 38, 2780-2795 (2018).

25. Yang, J. et al. Cereblon suppresses the lipopolysaccharide-induced inflammatory response by promoting the ubiquitination and degradation of C-Jun. J. Biol. Chem. 293, 10141-10157 (2018).

26. Krönke, J. et al. Lenalidomide causes selective degradation of IKZF1 and IKZF3 in multiple myeloma cells. Science 343, 301-305 (2014).

27. Lu, G. et al. The myeloma drug lenalidomide promotes the cereblondependent destruction of Ikaros proteins. Science 343, 305-309 (2014).

28. Lu, J. et al. Hijacking the E3 ubiquitin ligase cereblon to efficiently target BRD4. Chem. Biol. 22, 755-763 (2015).

29. Lai, A. C. \& Crews, C. M. Induced protein degradation: an emerging drug discovery paradigm. Nat. Rev. Drug Discov. 16, 101-114 (2017).

30. Kang, J.-A. et al. Epigenetic regulation of Kcna3-encoding Kv1.3 potassium channel by cereblon contributes to regulation of $\mathrm{CD}^{+}{ }^{+}$T-cell activation. Proc. Natl. Acad. Sci. USA 113, 8771-8776 (2016).

31. Zhou, L., Hao, Z., Wang, G. \& Xu, G. Cereblon suppresses the formation of pathogenic protein aggregates in a p62-dependent manner. Hum. Mol. Genet. 27, 667-678 (2018).
32. Min, Y. et al. Cereblon negatively regulates TLR4 signaling through the attenuation of ubiquitination of TRAF6. Cell Death Dis. 7, e2313 (2016).

33. Higgins, J. J., Pucilowska, J., Lombardi, R. Q. \& Rooney, J. P. A mutation in a novel ATP-dependent Lon protease gene in a kindred with mild mental retardation. Neurology 63, 1927-1931 (2004).

34. Xu, G., Jiang, X. \& Jaffrey, S. R. A mental retardation-linked nonsense mutation in cereblon is rescued by proteasome inhibition. J. Biol. Chem. 288, 29573-29585 (2013).

35. Sheereen, $\mathrm{A}$. et al. A missense mutation in the CRBN gene that segregates with intellectual disability and self-mutilating behaviour in a consanguineous Saudi family. J. Med. Genet. 54, 236-240 (2017).

36. Hu, J., McCall, C. M., Ohta, T. \& Xiong, Y. Targeted ubiquitination of CDT1 by the DDB1-CUL4A-ROC1 ligase in response to DNA damage. Nat. Cell Biol. $\mathbf{6}$, 1003-1009 (2004)

37. Petroski, M. D. \& Deshaies, R. J. Function and regulation of cullin-RING ubiquitin ligases. Nat. Rev. Mol. Cell Biol. 6, 9-20 (2005).

38. Alekseev, S. et al. Cellular concentrations of DDB2 regulate dynamic binding of DDB1 at UV-induced DNA damage. Mol. Cell. Biol. 28, 7402-7413 (2008).

39. Hannah, J. \& Zhou, P. Regulation of DNA damage response pathways by the cullin-RING ubiquitin ligases. DNA Repair (Amst.). 8, 536-543 (2009).

40. Li, J. M. \& Jin, J. CRL ubiquitin ligases and DNA damage response. Front. Oncol. 2, 29 (2012).

41. Karpinich, N. O., Tafani, M., Rothman, R. J., Russo, M. A. \& Farber, J. L. The course of etoposide-induced apoptosis from damage to DNA and p53 activation to mitochondrial release of cytochrome c. J. Biol. Chem. 277, 16547-16552 (2002).

42. Jamil, S., Lam, I., Majd, M., Tsai, S.-H. \& Duronio, V. Etoposide induces cell death via mitochondrial-dependent actions of p53. Cancer Cell. Int. 15, 79 (2015).

43. Tao, J., Yang, J. \& Xu, G. The interacting domains in cereblon differentially modulate the immunomodulatory drug-mediated ubiquitination and degradation of its binding partners. Biochem. Biophys. Res. Commun. 507, 443-449 (2018).

44. Lee, J. S. et al. Safety and efficacy of intraperitoneal injection of etoposide in oil suspension in mice with peritoneal carcinomatosis. Cancer Chemother. Pharmacol. 36, 211-216 (1995).

45. Borges, H. L., Linden, R. \& Wang, J. Y. J. DNA damage-induced cell death: lessons from the central nervous system. Cell Res. 18, 17-26 (2008).

46. Arbour, N. et al. MCl-1 is a key regulator of apoptosis during CNS development and after DNA damage. J. Neurosci. 28, 6068-6078 (2008).

47. Sayan, B. S., Sayan, A. E., Knight, R. A., Melino, G. \& Cohen, G. M. p53 is cleaved by caspases generating fragments localizing to mitochondria. J. Biol. Chem. 281, 13566-13573 (2006).

48. Grandela, C., Pera, M. F. \& Wolvetang, E. J. p53 is required for etoposideinduced apoptosis of human embryonic stem cells. Stem Cell Res. 1, 116-128 (2008).

49. Qin, $H$. et al. Regulation of apoptosis and differentiation by $p 53$ in human embryonic stem cells. J. Biol. Chem. 282, 5842-5852 (2007).

50. Zhu, Y. X. et al. Cereblon expression is required for the antimyeloma activity of lenalidomide and pomalidomide. Blood 118, 4771-4779 (2011).

51. Boyd, K. D. et al. The clinical impact and molecular biology of del(17p) in multiple myeloma treated with conventional or thalidomide-based therapy. Gene Chromosomes Cancer 50, 765-774 (2011).

52. Díaz-Rodríguez, E. \& Pandiella, A. Modulation of cereblon levels by antimyeloma agents. Leuk. Lymphoma 57, 167-176 (2016).

53. Lopez-Girona, A. et al. Cereblon is a direct protein target for immunomodulatory and antiproliferative activities of lenalidomide and pomalidomide. Leukemia 26, 2326-2335 (2012).

54. Rajadhyaksha, A. M. et al. Behavioral characterization of cereblon forebrainspecific conditional null mice: a model for human non-syndromic intellectual disability. Behav. Brain Res. 226, 428-434 (2012).

55. Hajdu, I., Ciccia, A., Lewis, S. M. \& Elledge, S. J. Wolf-Hirschhorn syndrome candidate 1 is involved in the cellular response to DNA damage. Proc. Natl Acad. Sci. USA 108, 13130-13134 (2011).

56. Alpatov, R. et al. A chromatin-dependent role of the fragile $X$ mental retardation protein FMRP in the DNA damage response. Cell 157, 869-881 (2014).

57. Wang, Y. \& Qin, Z. H. Coordination of autophagy with other cellular activities. Acta Pharmacol. Sin. 34, 585-594 (2013).

58. Zhang, S.-M., Shang, Z.-F. \& Zhou, P.-K. Autophagy as the effector and player in DNA damage response of cells to genotoxicants. Toxicol. Res. 4, 613-622 (2015). 
59. Yan, Q. et al. Activation of AMPK/mTORC1-mediated autophagy by metformin reverses Clk1 deficiency-sensitized dopaminergic neuronal death. Mol. Pharmacol. 92, 640-652 (2017).

60. White, E. Autophagy and p53. Cold Spring Harb. Perspect. Med. 6, a026120 (2016).

61. Fan, J. et al. DJ-1 decreases Bax expression through repressing p53 transcriptional activity. J. Biol. Chem. 283, 4022-4030 (2008).

62. Ren, H., Fu, K., Wang, D., Mu, C. \& Wang, G. Oxidized DJ-1 interacts with the mitochondrial protein BCL-X. J. Biol. Chem. 286, 35308-35317 (2011).

63. Chen, D. et al. Parkin mono-ubiquitinates $\mathrm{BCl}-2$ and regulates autophagy. J. Biol. Chem. 285, 38214-38223 (2010)
64. Wu, J. Y. et al. Protease Omi cleaving Hax-1 protein contributes to OGD/Rinduced mitochondrial damage in neuroblastoma N2a cells and cerebral injury in MCAO mice. Acta Pharmacol. Sin. 36, 1043-1052 (2015).

65. Zhou, L. et al. BCl-2-dependent upregulation of autophagy by sequestosome 1/p62 in vitro. Acta Pharmacol. Sin. 34, 651-656 (2013).

66. Zhou, L. et al. p62/Sequestosome 1 regulates aggresome formation of pathogenic ataxin-3 with expanded polyglutamine. Int. J. Mol. Sci. 15, 14997-15010 (2014)

67. Hou, X. et al. Parkin represses 6-hydroxydopamine-induced apoptosis via stabilizing scaffold protein p62 in PC12 cells. Acta Pharmacol. Sin. 36, 1300-1307 (2015) 